\title{
Pertumbuhan dan Potensi Produksi Beberapa Genotipe Jarak Pagar (Jatropha curcas L.) di Tanah Masam
}

\author{
Growth and Production of Physic Nut (Jatropha curcas L.) Genotypes on Acid Soil
}

\author{
Indah Retnowati, Memen Surahman*
}

Departemen Agronomi dan Hortikultura, Fakultas Pertanian, Institut Pertanian Bogor (Bogor Agricultural University), Jl. Meranti, Kampus IPB Darmaga, Bogor 16680, Indonesia Telp.\&Faks.62-251-8629353 e-mail agronipb@indo.net.id

\begin{abstract}
Indonesia has extensive acid soil but its utility is still limited because of its low nutrient content. Jatropha is a plant which can grow on various soil types, includes on marginal one, and has used as raw material for biodiesel. Therefore, the growth of jatropha on acid soil need to be studied as an effort for developing jatropha and utility of acid soil in Indonesia. To initiate the effort, research to grow various jatropha genotypes on acid soil was done. The objectives of this research was to obtain a potential tolerant jatropha genotype for acid soil. The research was conducted at UPTD Development of Dryland Technology at Singabraja Village, Tenjo Subdistrict, Bogor, West Java, from November 2010 - August 2011. This research using Randomized Complete Design Block Design (RCBD) with jatropha genotype as factor. The result showed that there were differences in growth among the jatropha genotypes. There are five jatropha genotypes with better growth in acid soil (pH 5.0) compare to others, i.e. Medan I-5-1, Dompu, IP-2P-3-4-1, Sulawesi, and Bima M.
\end{abstract}

Keywords: physic nut, genotypes, Jatropha curcas, acid soil

\section{ABSTRAK}

Indonesia memiliki tanah masam yang luas, tetapi kegunaan lahan ini masih sedikit karena kandungan hara pada tanah masam rendah. Jarak pagar adalah tanaman yang dapat tumbuh di berbagai jenis lahan, termasuk pada lahan marginal, dan telah digunakan sebagai bahan baku biodiesel. Oleh karena itu, penelitian mengenai pertumbuhan jarak pagar di tanah asam perlu dipelajari sebagai upaya untuk mengembangkan jarak pagar yang toleran tanah masam di Indonesia. Untuk memulai upaya itu, penelitian mengenai berbagai genotipe jarak pagar yang dapat tumbuh di tanah masam dilakukan. Tujuan dari penelitian ini adalah untuk memperoleh genotipe jarak pagar toleran tanah masam yang potensial. Penelitian ini dilakukan di UPTD Pengembangan Teknologi Lahan Kering Desa Singabraja, Kecamatan Tenjo, Bogor, Jawa Barat, dari bulan November 2010 - Agustus 2011. Penelitian ini menggunakan Rancangan Acak Kelompok Lengkap (RAKL) dengan satu faktor, yaitu genotipe. Hasil penelitian menunjukkan bahwa ada perbedaan pertumbuhan antara genotipe jarak pagar. Umumnya, ada lima genotipe jarak pagar dengan pertumbuhan terbaik di tanah masam (pH 5.0), yaitu Medan I-5-1, Dompu, IP-2P-3-4-1, Sulawesi, dan Bima M.

Kata kunci: genotipe, jarak pagar, Jatropha curcas, tanah masam

\section{PENDAHULUAN}

Konsumsi energi global saat ini mencapai sekitar 400 EJ per tahun. Konsumsi ini akan terus

\footnotetext{
* Penulis untuk korespondensi. e-mail: memensurahman@yahoo. com
}

meningkat hingga tahun-tahun mendatang seiring dengan peningkatan populasi penduduk dan pertumbuhan ekonomi global. Upaya pemenuhan kebutuhan energi tersebut tidak akan efektif bila hanya menumpukan pada suplai bahan bakar fosil yang persediannya makin hari makin menipis. Konsumsi

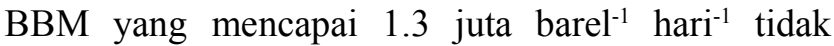


seimbang dengan produksi yang nilainya sekitar 1 juta barel ${ }^{-1}$ hari $^{-1}$ sehingga terdapat defisit yang harus dipenuhi melalui impor (Pambudi, 2008).

Upaya untuk memenuhi kebutuhan energi dan mengatasi krisis bahan bakar minyak fosil mendorong terhadap pencarian sumber bahan bakar alternatif. Salah satu sumber bahan bakar alternatif yang diminati adalah tanaman. Jenis bahan bakar dari tanaman ini disebut juga biofuel. Contoh biofuel adalah biodiesel, bioetanol (gasohol), dan bio-oil. Biodiesel dapat dibuat dari minyak mentah kelapa sawit (Crude Palm

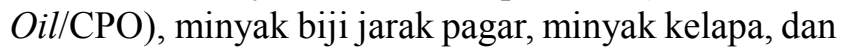
tanaman lainnya.

Saat ini jarak pagar (Jatropha curcas L.) menjadi salah sumber biofuel yang cukup diminati. Hal itu dikarenakan minyak jarak pagar merupakan energi alternatif yang ramah lingkungan dan lebih fleksibel dibandingkan dengan kelapa sawit dari segi biaya, perawatan, dan produksinya (Giwangkara, 2006). Produksi buah jarak pagar berkisar 7.5 - 10 ton ha $^{-1}$ tahun $^{-1}$ (Pambudi, 2008). Jarak pagar juga merupakan tanaman yang mudah beradaptasi dengan kondisi lingkungan dan dapat ditanam di berbagai jenis lahan, termasuk lahan kritis (Sumpena, 2007).

Jarak pagar sebagai tanaman penghasil biofuel yang ramah lingkungan mampu tumbuh di berbagai jenis lahan. Mahmud (2006) menyatakan jarak pagar dapat tumbuh pada tanah dengan ketersediaan air dan unsur hara yang terbatas (marjinal), bahkan jika kondisi perakarannya telah berkembang dengan baik, jarak pagar dapat tumbuh (toleran) pada lahan yang masam. Jarak pagar juga dapat ditanam pada daerah berbatu, berlereng, dan berbukit, atau sepanjang saluran air dan batas kebun.

Indonesia merupakan salah satu negara yang memiliki banyak lahan masam. Hal itu disebabkan Indonesia merupakan negara beriklim tropika basah. Menurut Nursanti dan Rohim (2009) lahan kering tergolong jenis tanah yang suboptimal untuk diusahakan pertanian karena kurang subur, bereaksi masam, serta mengandung $\mathrm{Al}, \mathrm{Fe}$, atau $\mathrm{Mn}$ dalam jumlah tinggi sehingga dapat meracuni tanaman. Lahan masam juga pada umumnya miskin bahan organik dan hara makro, seperti N, P, K, Ca, dan Mg.

Salah satu solusi yang dapat dilakukan agar lahan masam dapat dimanfaatkan untuk kegiatan pertanian adalah dengan menanam tanaman yang toleran dengan tanah masam. Jarak pagar sebagai tanaman berpotensi untuk bahan baku biofuel yang dapat ditanam di berbagai jenis tanah menjadi pilihan untuk dicobatanamkan di lahan masam. Pada penelitian ini akan dilakukan pengamatan pertumbuhan berbagai genotipe jarak pagar di lahan masam agar diketahui genotipe yang tahan (toleran) untuk dikembangkan di lahan masam. Penelitian ini bertujuan untuk mengetahui pertumbuhan beberapa genotipe jarak pagar di tanah masam

\section{BAHAN DAN METODE}

Penelitian ini dilaksanakan mulai bulan November 2010 sampai Agustus 2011. Penelitian ini dilaksanakan di UPTD Pengembangan Teknologi Lahan Kering Desa Singabraja, Kecamatan Tenjo, Kabupaten Bogor, Jawa Barat. Lokasi penelitian terletak pada $57 \mathrm{~m} \mathrm{dpl}$, memiliki tekstur tanah liat dengan pH (H20) sebesar 5.0 (masam). Kejenuhan Al, kandungan C-organik dan N-organik, dan kapasitas tukar kation dalam tanah tergolog rendah. Hara $\mathrm{P}$ potensial tergolong sedang dengan P-tersedia sangat tinggi. Kalium potensial pada lahan penanaman tergolong sangat rendah dengan K-tersedia sebesar $27 \mathrm{ppm} \mathrm{K2O}$. Kejenuhan basa sangat tinggi yang mencerminkan tingginya kandungan garam tanah terlarut. Bahan yang digunakan adalah 16 genotipe jarak pagar, pupuk, dan insektisida. Penanaman genotipe di lapangan diatur dalam rancangan kelompok teracak lengkap (RKLT). Pupuk yang digunakan adalah pupuk kimia berupa Urea (50 kg ha-1), SP-36 (250kg ha-1), dan $\mathrm{KCl}$ (50 kg ha-1). Insektisida yang digunakan adalah Dursban (pembibitan) dan furadan (penanaman) secukupnya.

Pengamatan dilakukan setiap dua minggu sekali sejak tanaman dipindahtanamkan dari pembibitan ke lapang. Kegiatan pengamatan terdiri atas pengamatan di akhir pembibitan dan pengamatan di lapangan. Pengamatan di akhir pembibitan dilakukan terhadap tujuh peubah yaitu: (1) daya berkecambah, dengan menghitung persentase kecambah normal terhadap jumlah benih yang ditanam per genotipe, (2) tinggi bibit, pengamatan dilakukan pada 3 bibit contoh dengan mengukur bibit dari permukaan tanah sampai titik tumbuh, (3) jumlah daun, menghitung jumlah daun pada 3 bibit contoh per genotipe, (4) panjang akar $(\mathrm{cm})$, mengukur dari pangkal sampai ujung akar pada 3 bibit contoh per genotipe yang dibongkar dari media tanam, (5) tinggi tajuk (cm), mengukur dari pangkal batang sampai ujung batang pada 3 bibit contoh per genotipe yang dibongkar dari media tanam, (6) bobot kering akar (g), dilakukan dengan cara menimbang akar yang telah dioven pada suhu 60 oC selama empat hari pada 3 bibit contoh per genotipe, dan (7) bobot kering tajuk (g), dilakukan dengan cara menimbang tajuk yang telah dioven pada suhu $600 \mathrm{C}$ selama empat hari pada 3 bibit contoh per genotipe.

Pengamatan di lapangan dilakukan terhadap 
14 peubah. Penjelasan pengambilan data masingmasing peubah adalah sebagai berikut: (1) tinggi tanaman $(\mathrm{cm})$, diukur pada batang utama mulai dari permukaan tanah sampai ujung tanaman setiap dua minggu; (2) jumlah daun, dengan menghitung jumlah daun pada tanaman setiap dua minggu; (3) jumlah cabang primer, menghitung cabang primer tanaman setiap dua minggu; (4) jumlah cabang produktif, menghitung cabang tanaman yang menghasilkan buah; (5) jumlah malai per tanaman, menghitung jumlah malai pada setiap tanaman; (6) waktu 50\% berbunga, mencatat waktu (minggu) tanaman jarak pagar berbunga 50\% untuk setiap genotipe; (7) waktu bunga mekar pertama, yaitu waktu (hari) saat bunga tanaman jarak pagar (betina atau jantan) mekar pertama kali untuk setiap genotipe, dimana bunga mekar adalah saat kuncup bunga jantan atau betina telah membuka sempurna; (8) jumlah bunga betina/hermaprodit per malai, menghitung jumlah bunga betina/hermaprodit yang dihasilkan oleh setiap tanaman pada tiga malai yang terbentuk pertama kali; (9) jumlah tanaman berbunga, menghitung jumlah tanaman jarak pagar yang berbunga untuk setiap genotipe, dimana tanaman berbunga adalah saat tanaman mulai menghasilkan kuncup bunga; (10) jumlah tanaman berbuah, menghitung jumlah tanaman jarak pagar yang berbuah untuk setiap genotipe; (11) jumlah buah per malai, menghitung jumlah buah yang dihasilkan oleh setiap tanaman pada tiga malai pertama; (12) jumlah buah per tanaman, menghitung jumlah buah yang diproduksi oleh setiap tanaman; (13) jumlah buah per bulan, menghitung jumlah buah yang dipanen setiap bulan untuk tiap genotipe; dan (14) produksi biji kering per tanaman, menimbang biji kering yang diproduksi oleh setiap tanaman. Analisis data dilakukan dengan uji-F diikuti uji jarak berganda Duncan (DMRT) untuk peubah yang berbeda nyata.

\section{HASIL DAN PEMBAHASAN}

\section{Fase Vegetatif}

Rata-rata tinggi dan jumlah daun bibit yang normal saat 2 bulan setelah semai adalah $15.3 \mathrm{~cm}$ dan 6 daun. Tinggi tajuk bibit antar genotipe berkisar 19 - $24 \mathrm{~cm}$, kecuali genotipe Thailand dan Parung Panjang 4. Kedua genotipe ini memiliki tajuk yang jauh lebih pendek dibandingkan genotipe lain. Bobot tajuk Thailand dan Parung Panjang 4 pun memiliki bobot terendah, yaitu kurang dari $1 \mathrm{~g}$, sementara Bima M memiliki bobot tajuk terberat mencapai $4.94 \mathrm{~g}$ dengan tajuk paling panjang, yaitu $24.5 \mathrm{~cm}$. Panjang akar bibit setiap genotipe jarak pagar beragam antara
$11-20 \mathrm{~cm}$. Genotipe dengan panjang akar maksimum dan minimum adalah IP-1M dan Banten I-5-1 dengan panjang $20.2 \mathrm{~cm}$ dan $11.2 \mathrm{~cm}$. Bobot akar bibit jarak pagar berkisar antara $0.08-0.29 \mathrm{~g}$, bobot yang sangat rendah bila dibandingkan dengan hasil penelitian Santoso et al. (2009) yang berkisar antara $0.58-0.88 \mathrm{~g}$. Perbedaan hasil ini diduga karena penggunaan media pembibitan yang berbeda. Banten I-5-1 merupakan genotipe dengan bobot akar maksimum, sebaliknya Thailand memiliki bobot akar minimum.

Genotipe dengan pertumbuhan bibit terbaik adalah Banten I-4-1, IP-2P-3-4-1, dan Bima M, sebaliknya Parung Panjang 4 dan Thailand memiliki pertumbuhan bibit terendah. Sementara itu, untuk pengamatan di akhir pembibitan, yang teramati dari genotipe Sulawesi hanya daya berkecambah karena jumlah bibit yang tersisa cukup untuk bahan tanaman di lapang.

Hasil sidik ragam menunjukkan bahwa perlakuan genotipe berpengaruh sangat nyata terhadap jumlah daun dan jumlah cabang primer jarak pagar. Perlakuan genotipe tidak berpengaruh terhadap tinggi tanaman, yang artinya setiap genotipe jarak pagar yang digunakan dalam penelitian memiliki respon pertumbuhan tinggi yang sama di tanah masam. Hal ini diduga karena potensi genetik jarak pagar untuk membentuk tanaman perdu.

Hasil penelitian menunjukkan rataan tinggi tanaman pada 14 MST mencapai $78.8 \mathrm{~cm}$ dengan nilai pengamatan maksimum $92.5 \mathrm{~cm}$ dan minimum $66.3 \mathrm{~cm}$ (Tabel 3). Rataan tinggi yang diperoleh dalam penelitian ini masih lebih rendah dibandingkan dengan hasil penelitian Prasetyo et. al., dimana pada umur 10 MST tinggi maksimum dan minimum yang dicapai oleh jarak pagar adalah 116.75 cmdan 100.94 $\mathrm{cm}$. Genotipe dengan rataan tinggi tanaman maksimum adalah IP-2P-3-4-1, sedangkan Banten I-5-1 memiliki rataan tinggi tanaman minimum.

Perlakuan genotipe berpengaruh sangat nyata terhadap peubah jumlah daun (Tabel 2) dengan rataan mencapai 147.3 daun, meliputi nilai pengamatan maksimum 215.3 daun dan minimum 86.3 daun (Tabel 3). Hal ini berarti bahwa 16 genotipe jarak pagar memiliki respon yang berbeda untuk peubah jumlah daun saat ditanam pada tanah masam, dimana penyebab perbedaan respon ini diduga karena defisiensi hara. Genotipe yang toleran terhadap defisiensi hara di tanah masam dapat menghasilkan jumlah daun yang tidak berbeda dengan jarak pagar yang ditanam pada lahan dengan $\mathrm{pH}$ normal, sementara genotipe yang tidak toleran menghasilkan jumlah daun yang jauh lebih sedikit dari kondisi normal. 
Tabel 1. Nilai rataan pertumbuhan vegetatif jarak pagar di pembibitan saat 2 bulan setelah semai

\begin{tabular}{lccccccc}
\hline Genotipe & DB (\%) & $\begin{array}{c}\text { Tinggi } \\
(\mathrm{cm})\end{array}$ & $\sum$ Daun & $\begin{array}{c}\text { Panj. Tajuk } \\
(\mathrm{cm})\end{array}$ & $\begin{array}{c}\text { Bobot Tajuk } \\
(\mathrm{g})\end{array}$ & $\begin{array}{c}\text { Panj. Akar } \\
(\mathrm{cm})\end{array}$ & $\begin{array}{c}\text { Bobot } \\
\text { Akar } \\
(\mathrm{g})\end{array}$ \\
\hline Ban I-3-1 & 56 & 18.6 & 6.0 & 23.7 & 2.01 & 15.8 & 0.19 \\
Ban I-4-1 & 84 & 17.2 & 6.0 & 23.6 & 4.27 & 12.0 & 0.17 \\
Ban I-5-1 & 64 & 15.3 & 6.0 & 22.4 & 1.58 & 11.2 & 0.29 \\
Ban III-2-1 & 56 & 16.0 & 6.0 & 20.0 & 1.56 & 16.8 & 0.19 \\
Parung P 4 & 20 & 10.7 & 5.0 & 15.5 & 0.99 & 12.5 & 0.11 \\
Bima F & 48 & 16.1 & 7.0 & 21.4 & 0.58 & 16.4 & 0.15 \\
Bima M & 80 & 16.1 & 6.0 & 24.5 & 4.94 & 11.5 & 0.15 \\
Dompu & 80 & 14.1 & 5.0 & 20.8 & 1.87 & 15.7 & 0.10 \\
G.Tambora & 64 & 16.5 & 6.0 & 23.3 & 1.93 & 14.9 & 0.11 \\
Lombok & 52 & 17.3 & 7.0 & 23.3 & 3.49 & 18.8 & 0.16 \\
Aceh Besar & 72 & 13.9 & 4.0 & 19 & 1.58 & 13.8 & 0.13 \\
Med I-5-1 & 60 & 14.9 & 5.0 & 18.9 & 1.84 & 19.4 & 0.18 \\
Thailand & 28 & 10.0 & 6.0 & 14.7 & 0.84 & 13.1 & 0.08 \\
Sulawesi & 28 & 16.3 & 6.0 & - & - & - & - \\
IP-1M & 32 & 15.9 & 4.0 & 22.4 & 3.71 & 20.2 & 0.17 \\
IP-2P-3-4-1 & 84 & 16.6 & 6.0 & 23.6 & 2.22 & 15.4 & 0.16 \\
Rataan & 59 & 15.3 & 5.6 & 21.1 & 2.20 & 15.2 & 0.20 \\
\hline
\end{tabular}

Peningkatan jumlah daun 16 genotipe jarak pagar tidak jauh berbeda dengan tinggi tanaman. Jumlah daun tanaman meningkat lambat hingga 6 MST, kemudian meningkat cepat pada 6-12 MST, tetapi setelah 12 MST laju peningkatan daun menjadi negatif. Hal ini terjadi karena proses alami jarak pagar, dimana tanaman ini akan menggugurkan daunnya ketika telah memasuki fase generatif. Saat fase generatif mulai habis, jumlah daun kembali bertambah, yang menjadi tanda bahwa fase vegetatif kembali dimulai.

Genotipe yang mengalami peningkatan negatif setelah 12 MST adalah Banten I-4-1, Banten I-5-1, Banten III-2-1, Lombok, Gunung Tambora, Bima F, Dompu, dan Aceh Besar, sementara sisanya mengalami peningkatan negatif setelah 14 MST.

Perlakuan genotipe berpengaruh sangat nyata terhadap peubah jumlah cabang primer jarak pagar yang ditanam di tanah masam (Tabel 2). Rataan jumlah cabang primer yang dihasilkan oleh tanaman adalah 3.6 cabang dengan nilai maksimum 7 cabang dan nilai minimum 1.3 cabang (Tabel 3 ).

Pembentukan cabang primer menjadi salah satu peubah penting untuk mengetahui genotipe jarak pagar yang toleran terhadap tanah masam. Menurut Raden et al. (2009) cabang tempat tumbuhnya bunga dan buah jarak pagar sangat ditentukan oleh cabang primer dan sekunder yang tumbuh dari batang utama.

Genotipe dengan cabang primer paling banyak adalah Banten I-4-1 dan Gunung Tambora, sebanyak 7 cabang. Penelitian Nisya (2010) genotipe Banten hanya menghasilkan 1.8 cabang primer, sementara penelitian Misnen (2010) menyebutkan bahwa genotipe Gunung Tambora menghasilkan 8 cabang. Jika ketiga hasil penelitian ini dibandingkan, dapat diduga bahwa untuk peubah jumlah cabang primer, genotipe Banten I-4-1 lebih toleran terhadap tanah masam dibandingkan genotipe Gunung Tambora dan seluruh genotipe Banten,

Tabel 2. Rekapitulasi hasil analisis ragam peubah pengamatan vegetatif pada 14 MST

\begin{tabular}{lccc}
\hline Peubah & $\begin{array}{c}\text { Pengaruh } \\
\text { kelompok }\end{array}$ & $\begin{array}{c}\text { Pengaruh } \\
\text { genotipe }\end{array}$ & $\begin{array}{c}\text { KK } \\
(\%)\end{array}$ \\
\hline Tinggi Tanaman & tn & tn & 12.50 \\
Jumlah Daun & tn & $* *$ & 23.67 \\
Jumlah Cabang & tn & $* *$ & 17.17 \\
Primer & & & \\
\hline
\end{tabular}

Keterangan $: \operatorname{tn}=$ tidak nyata, $*=$ nyata, $* *=$ sangat nyata 
Tabel 3. Pengaruh genotipe terhadap tinggi tanaman, jumlah daun, dan jumlah cabang primer jarak pagar di tanah masam

\begin{tabular}{lccccc}
\hline Genotipe & $\begin{array}{c}\text { Tinggi } \\
\text { Tan. } \\
\text { (cm) }\end{array}$ & $\begin{array}{c}\text { Jumlah } \\
\text { Daun }\end{array}$ & \multicolumn{3}{c}{$\begin{array}{c}\text { Jumlh } \\
\text { Cabang } \\
\text { Primer }\end{array}$} \\
\hline Banten I-3-1 & 88.0 & 112.3 & bc & 1.333 & $\mathrm{~d}$ \\
Banten I-4-1 & 70.3 & 215.3 & $\mathrm{a}$ & 7.000 & $\mathrm{a}$ \\
Banten I-5-1 & 66.3 & 160.7 & $\mathrm{ab}$ & 6.333 & $\mathrm{a}$ \\
Banten III-2-1 & 69.9 & 174.7 & $\mathrm{ab}$ & 5.667 & $\mathrm{ab}$ \\
Parung & 79.9 & 121.3 & $\mathrm{bc}$ & 1.333 & $\mathrm{~cd}$ \\
Panjang 4 & & & & & \\
Bima F & 76.4 & 210.3 & $\mathrm{a}$ & 6.333 & $\mathrm{a}$ \\
Bima M & 88.6 & 109.0 & $\mathrm{bc}$ & 1.000 & $\mathrm{~d}$ \\
Dompu & 83.1 & 116.3 & $\mathrm{bc}$ & 2.000 & $\mathrm{~cd}$ \\
Gunung & 70.8 & 177.3 & $\mathrm{ab}$ & 7.000 & $\mathrm{a}$ \\
Tambora & & & & & \\
Lombok & 75.5 & 168.3 & $\mathrm{ab}$ & 6.333 & $\mathrm{a}$ \\
Aceh Besar & 80.0 & 130.0 & $\mathrm{bc}$ & 2.667 & $\mathrm{~cd}$ \\
Medan I-5-1 & 87.4 & 142.0 & $\mathrm{bc}$ & 2.000 & $\mathrm{~cd}$ \\
Sulawesi & 81.4 & 166.3 & $\mathrm{ab}$ & 3.333 & $\mathrm{bc}$ \\
Thailand & 82.0 & 140.0 & $\mathrm{bc}$ & 2.333 & $\mathrm{~cd}$ \\
IP-1M & 68.8 & 86.3 & $\mathrm{c}$ & 2.000 & $\mathrm{~cd}$ \\
IP-2P-3-4-1 & 92.5 & 126.0 & $\mathrm{bc}$ & 1.333 & $\mathrm{~cd}$ \\
Rataan & 78.8 & 147.3 & & 3.625 & \\
\hline
\end{tabular}

Keterangan : Angka-angka pada kolom yang sama dan diikuti huruf yang berbeda menunjukkan berbeda nyata berdasarkan uji DMRTpada taraf 5\%. Hasil transformasi akar $(\mathrm{x}+0.5)$

kecuali genotipe Banten I-3-1, dalam penelitian ini memiliki pembentukan cabang primer yang lebih baik pada tanah masam dibandingkan saat ditanam pada tanah $\mathrm{pH}$ normal.

Genotipe Bima M dalam penelitian ini memiliki satu cabang primer, sementara dalam penelitian Misnen (2010) genotipe ini mampu menghasilkan 7 cabang primer. Perbedaan hasil yang nyata ini juga dialami IP-2P-3-4-1, IP-1M, dan Dompu. Hal ini diduga bahwa keempat genotipe ini kurang toleran terhadap kondisi tanah asam untuk peubah jumlah cabang.

Genotipe dengan pertumbuhan vegetatif terbaik secara berturut-turut adalah Banten I-4-1, Bima F, dan Gunung Tambora. Genotipe yang memiliki pertumbuhan vegetatif terendah secara berturut-turut dari yang paling rendah adalah IP-1M dan Parung Panjang 4.

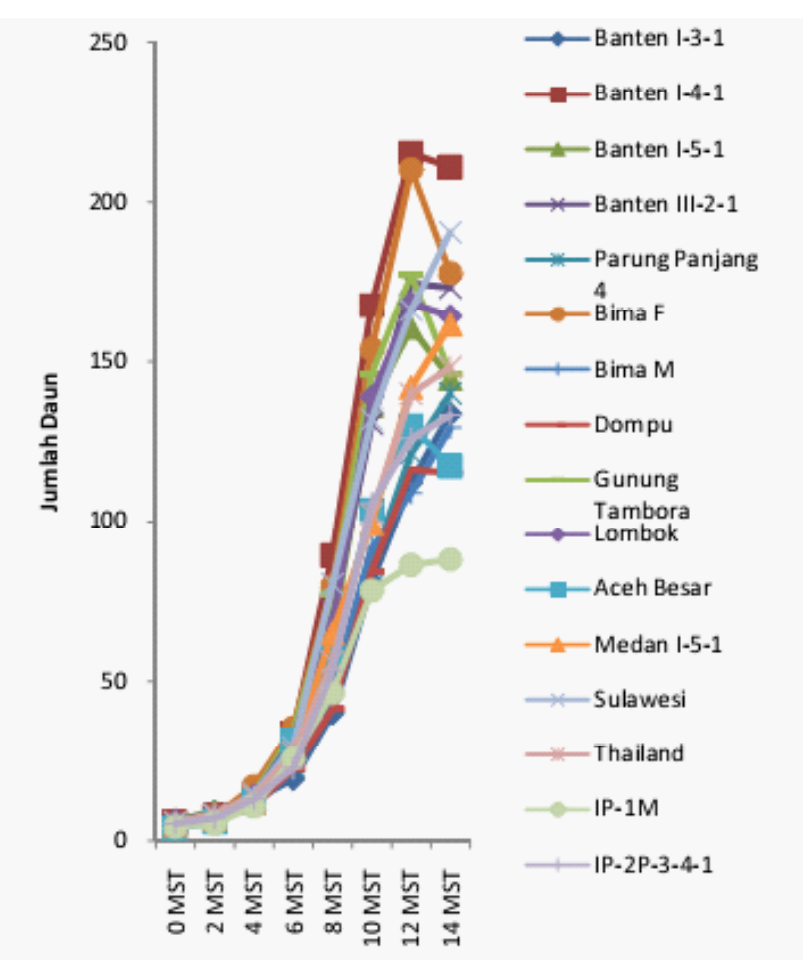

Gambar 1. Peningkatan jumlah daun 16 genotipe jarak pagar selama 14 MST

\section{Fase Generatif}

Hasil sidik ragam menunjukkan bahwa perlakuan genotipe berpengaruh sangat nyata terhadap seluruh peubah pengamatan generatif. Sementara itu, perlakuan pengelompokkan (ulangan) berpengaruh sangat nyata hanya terhadap peubah jumlah bunga betina per malai. Kelompok ketiga menghasilkan bunga betina/hermaprodit paling sedikit (112 bunga ulangan-1). Hasil ini diduga karena pertanamannya berdampingan langsung dengan tanaman ubi kayu ( \pm 2 meter) sehingga terjadi persaingan hara di antara keduanya. Jumlah gulma dan penyakit yang menyerang jarak pagar pada ulangan ketiga juga lebih banyak dibandingkan ulangan lainnya. Hal ini mengakibatkan tanaman sulit berbunga, khususnya bunga betina/hermaprodit.

Jarak pagar dapat berbunga pada usia 75 - 360 hari setelah tanam (Hartati et al., 2009). Pada penelitian ini jarak pagar berbunga lebih cepat, yaitu 70 - 154 hari setelah tanam. Percepatan pembungaan ini dapat disebabkan kondisi stres tanaman terhadap tanah masam sehingga jarak pagar mempercepat fase penuaannya yang ditandai dengan waktu pembungaan yang lebih cepat.

Beberapa tanaman dari Banten I-5-1, Aceh Besar, Banten III-2-1, dan Gunung Tambora, 
Tabel 4. Rekapitulasi hasil analisis ragam peubah pengamatan generatif

\begin{tabular}{lccc}
\hline Peubah & $\begin{array}{l}\text { Pengaruh } \\
\text { kelompok }\end{array}$ & $\begin{array}{c}\text { Pengaruh } \\
\text { Genotipe }\end{array}$ & $\begin{array}{c}\text { KK } \\
(\%)\end{array}$ \\
\hline $\begin{array}{l}\text { Cabang } \\
\text { Produktif } \\
(19 M S B)\end{array}$ & th & $* *$ & 18.02 \\
$\begin{array}{l}\text { Jumlah Malai } \\
(19 \text { MSB })\end{array}$ & tn & $* *$ & 17.99 \\
$\begin{array}{l}\text { Bunga Betina } \\
\text { per Malai }\end{array}$ & $* *$ & $* *$ & 14.02 \\
$\begin{array}{l}\text { Buah per } \\
\text { Malai }\end{array}$ & tn & $* *$ & 23.18 \\
$\begin{array}{l}\text { Jumlah Buah } \\
\text { Bobot Biji }\end{array}$ & tn & $* *$ & 22.78 \\
\hline
\end{tabular}

Keterangan : tn $=$ tidak nyata, $*=$ nyata, $* *=$ sangat nyata, $\mathrm{MSB}=$ minggu setelah berbunga

tidak menghasilkan bunga dan terus menunjukkan pertumbuhan vegetatif hingga masa pengamatan generatif berakhir. Genotipe Banten I-5-1 memiliki 7 tanaman berbunga dari 9 tanaman yang diamati, sementara ketiga genotipe lainnya menghasilkan 8 tanaman berbunga. Beberapa tanaman yang tidak menghasilkan bunga menunjukkan keterlambatan pertumbuhan, terlihat dari bentuk tanaman yang kerdil $(<50 \mathrm{~cm})$. Menurut Nisya (2010) keterlambatan pembungaan ini diduga karena sebagian besar energi yang dihasilkan jarak pagar digunakan untuk memproduksi senyawa antioksidan untuk melindungi sel dari bahaya radikal bebas (reactive oxygen species).

Waktu $50 \%$ berbunga merupakan tolok ukur peralihan tanaman dari fase vegetatif menuju fase generatif. Hasil penelitian menunjukkan bahwa ada tujuh genotipe yang memiliki waktu $50 \%$ berbunga tercepat (10 MST), yaitu Banten I-3-1, Bima M, Dompu, Medan I-5-1, Sulawesi, Thailand, dan IP2P-3-4-1 (Tabel 5). Genotipe-genotipe ini memiliki waktu pembungaan yang serempak. Genotipe jarak pagar lainnya memiliki variasi waktu $50 \%$ berbunga antara 12 - 17 MST, dimana waktu pembungaannya juga bervariasi (tidak serempak). Genotipe yang paling lambat waktu berbunga 50\%-nya adalah Banten I-5-1 dan Gunung Tambora. Keterlambatan pembungaan Gunung Tambora dalam penelitian ini (17 MST) diduga disebabkan kondisi lingkungan, seperti curah hujan yang ber-fluktuasi pada fase pembungaan, kekurangan hara, dan penggunaan energi yang dihasilkan untuk memproduksi senyawa antioksidan.

Waktu mekar bunga jarak pagar antara 3 - 4 minggu setelah berbunga (MSB). Genotipe yang berbunga $50 \%$ pada $10 \mathrm{MST}$ akan mekar bunganya pada 4 MSB, yaitu Banten I-3-1, Bima M, Dompu, Medan I-5-1, Sulawesi, Thailand, dan IP-2P-3-4-1. Genotipe dengan waktu mekar bunga \pm 3 MSB umumnya terjadi pada genotipe yang waktu berbunga 50\%-nya antara 11 - 15 MST, yaitu Banten I-4-1, Banten III-2-1, Parung Panjang 4, Lombok, Aceh Besar, dan IP-1M. Banten I-5-1 dan Bima F hanya memerlukan waktu dua minggu untuk mekar dari waktu $50 \%$ berbunga (Tabel 5). Perbedaan ini diduga karena perbedaan cuaca saat fase pembungaan. Pada $10-15$ MST curah hujan pada lokasi penelitian cukup tinggi dan mengakibatkan tanaman kurang mendapatkan cahaya matahari dan suhu yang cukup untuk proses pemekaran bunga. Memasuki bulan Mei jumlah curah hujan mulai menurun sehingga tanaman mendapatkan cahaya dan suhu yang cukup untuk proses pemekaran bunga. Nurcholis dan Sumarsih (2007) menjelaskan bahwa tanaman jarak pagar menghendaki suhu tinggi pada fase generatif. Genotipe jarak pagar yang mampu menghasilkan jumlah bunga betina/hermaprodit terbanyak, yaitu Dompu, Bima M, Banten I-3-1, dan Thailand. Keempat genotipe mampu menghasilkan bunga betina/hermaprodit $>10$ bunga. Genotipe yang paling sedikit menghasilkan bunga betina/hermaprodit adalah Banten III-2-1, Aceh Besar, dan Banten I-51. Pada penelitian Misnen dan Nisya (2010) juga menunjukkan bahwa Aceh Besar adalah genotipe yang sedikit menghasilkan bunga betina.

Rata-rata malai yang dihasilkan oleh setiap tanaman jarak pagar adalah 6 malai tanaman-1. Genotipe dengan malai terbanyak adalah Sulawesi, Medan I-5-1, Banten I-3-1, Parung Panjang 4, dan IP-2P-3-4-1, dimana genotipe- genotipe ini juga menghasilkan jumlah malai yang cukup banyak dalam penelitian Misnen dan Nisya (2010) Gunung Tambora, Banten I-5-1, dan IP-1M merupakan genotipe dengan jumlah malai paling sedikit dibandingkan dengan genotype lainnya. Hasil yang serupa juga terjadi pada Gunung Tambora dan IP-1M dalam penelitian Misnen (2010), dimana genotipe yang paling sedikit menghasilkan malai adalah Aceh Besar, IP-1M, dan Gunung Tambora. Pada penelitian ini pun Aceh Besar tidak menghasilkan malai yang cukup banyak.

Jarak pagar yang telah berbunga tidak selalu dapat menghasilkan buah.Bunga-bunga yang telah terbentuk, bahkan mengalami anthesis, dapat mengalami kerontokan karena faktor genetik maupun lingkungan. Pada penelitian ini hanya enam genotipe 
Tabel 5. Jumlah tanaman berbunga dan berbuah serta waktu berbunga dan waktu bunga mekar pertama 16 genotipe jarak pagar

\begin{tabular}{lcccc}
\hline Genotipe & $\begin{array}{c}\text { Tanaman } \\
\text { Berbunga } \\
(\%)\end{array}$ & $\begin{array}{c}\text { Tanaman } \\
\text { Berbuah } \\
(\%)\end{array}$ & $\begin{array}{c}\text { Waktu } \\
\text { \% berbunga } \\
(\text { MST })\end{array}$ & $\begin{array}{c}\text { Waktu } \\
\text { mekar pertama } \\
\text { (MSB) }\end{array}$ \\
\hline Banten I-3-1 & 100 & 100 & 10 & 4 \\
Banten I-4-1 & 100 & 67 & 16 & 3 \\
Banten I-5-1 & 78 & 44 & 17 & 2 \\
Banten III-2-1 & 89 & 56 & 16 & 3 \\
Parung Panjang & 100 & 100 & 12 & 3 \\
Bima F & 100 & 89 & 15 & 2 \\
Bima M & 100 & 89 & 10 & 4 \\
Dompu & 100 & 100 & 10 & 4 \\
G. Tambora & 89 & 67 & 17 & 3 \\
Lombok & 100 & 89 & 14 & 3 \\
Aceh Besar & 89 & 67 & 14 & 4 \\
Medan I-5-1 & 100 & 100 & 10 & 4 \\
Sulawesi & 100 & 100 & 10 & 4 \\
Thailand & 100 & 89 & 10 & 3 \\
IP-1M & 100 & 100 & 14 & 4 \\
IP-2P-3-4-1 & 100 & & 10 & \\
\hline
\end{tabular}

Keterangan : $\quad$ MST $=$ minggu setelah tanam, $\mathrm{MSB}=$ minggu setelah berbunga

yang tanaman contohnya $100 \%$ dapat menghasilkan buah, yaitu Banten I-3-1, Parung Panjang 4, Dompu, Sulawesi, Thailand, dan IP-2P-3-4-1, sedangkan persentase tanaman yang dapat berbuah untuk genotipe lainnya berkisar $40-90 \%$ dengan persentase tanaman berbuah terendah adalah Banten I-5-1(Tabel 5).

Genotipe Dompu menghasilkan buah terbanyak, yaitu 10 buah (Tabel 7) dari 13 bunga betina yang terbentuk per malainya (Tabel 6). Begitu pula dengan Bima $M$ dengan 9 buah dari 11 bunga betina malai-1. Rata-rata buah yang dihasilkan setiap malai dalam penelitian ini adalah enam buah, tidak berbeda nyata dengan hasil 7 buah malai-1 dalam penelitian Melisa (2011) dan 8 buah malai-1 dalam Nisya (2010). Pada penelitian ini, genotipe Medan I-5-1 mampu menghasilkan 8 buah malai-1, hasil yang sama diperoleh dalam penelitian Melisa (2011) untuk genotipe Medan. Genotipe Banten I-3-1 dan Bima ( $F$ dan $M$ ) menghasilkan buah sebanyak 7,6 , dan 9 buah per malai, hasil yang hampir sama dengan penelitian Nisya (2010) untuk genotipe Banten dan Bima, yaitu 7 dan 8 buah per malai.

Genotipe dengan hasil buah paling sedikit adalah Banten III-2-1 dan Aceh Besar, bahkan di antara genotipe Banten, Banten III-2-1 menunjukkan hasil terendah. Jika dibandingkan dengan genotipe Banten dalam penelitian Nisya (2010), penyebab rendahnya buah yang dihasilkan oleh Banten III-21 dapat diduga karena tanaman genotipe ini kurang toleran terhadap tanah masam, meskipun keragaan vegetatif genotipe ini tampak sangat subur. Aceh Besar menghasilkan 3 buah malai-1, genotipe ini adalah salah satu genotipe dengan produksi buah terendah (Nisya, 2010).

Jumlah buah panen per bulan dari 16 genotipe berkisar $7-89$ buah dengan rata-rata 47 buah/bulan. Jumlah buah panen/bulan paling banyak dihasilkan oleh genotipe Dompu dan IP-2P-3-4-1 sebanyak 89 buah, sedangkan jumlah buah panen bulan-1 yang paling sedikit dihasilkan oleh Banten I-5-1 sebanyak 7 buah. Genotipe Banten I-5-1 dan Banten III-21 hanya mengalami tiga bulan masa panen dengan kisaran panen per bulan $3-15$ buah. Begitu pula dengan genotipe Banten I-4-1, Aceh Besar, dan IP$1 \mathrm{M}$ dengan waktu panen tiga bulan (Juni - Agustus) hanya menghasilkan $26-29$ buah jarak pagar per bulan. Produksi yang lebih tinggi diperoleh genotipe Gunung Tambora yang menghasilkan 30 buah dalam waktu panen dua bulan (Juli - Agustus). Genotipe 
Tabel 6. Jumlah bunga betina/hermaprodit, jumlah malai, dan Jumlah cabang produktif 16 genotipe jarak pagar di tanah masam

\begin{tabular}{|c|c|c|c|}
\hline Genotipe & Jumlah Bunga Betina Malai-1 & $\sum$ Malai Tanaman-1 & $\sum$ Cabang Produktif \\
\hline Banten I-3-1 & $11.667 \mathrm{ab}$ & $8.667 \mathrm{abc}$ & $2.667 \mathrm{bc}$ \\
\hline Banten I-4-1 & $5.093 \mathrm{fg}$ & 5.333 cde & $2.000 \mathrm{bc}$ \\
\hline Banten I-5-1 & $3.750 \mathrm{gh}$ & $2.667 \mathrm{e}$ & $1.333 \mathrm{c}$ \\
\hline Banten III-2-1 & $2.720 \mathrm{~h}$ & $3.667 \mathrm{de}$ & $1.500 \mathrm{c}$ \\
\hline Parung Panjang 4 & $8.223 \mathrm{de}$ & $8.667 \mathrm{abc}$ & $2.667 \mathrm{bc}$ \\
\hline Bima F & $8.567 \mathrm{~d}$ & $5.333 \mathrm{cde}$ & $3.333 \mathrm{bc}$ \\
\hline Bima M & $11.817 \mathrm{ab}$ & $7.667 \mathrm{abcd}$ & $2.333 \mathrm{bc}$ \\
\hline Dompu & $13.187 \mathrm{a}$ & $8.000 \mathrm{abc}$ & $3.333 \mathrm{bc}$ \\
\hline Gunung Tambora & $4.943 \mathrm{fg}$ & $2.333 \mathrm{e}$ & $2.000 \mathrm{bc}$ \\
\hline Lombok & $8.353 \mathrm{de}$ & 5.667 bcde & $2.333 \mathrm{bc}$ \\
\hline Aceh Besar & $3.193 \mathrm{gh}$ & 4.333 cde & $1.333 \mathrm{c}$ \\
\hline Medan I-5-1 & $9.890 \mathrm{bcd}$ & $10.333 \mathrm{ab}$ & $3.667 \mathrm{~b}$ \\
\hline Sulawesi & $9.553 \mathrm{~cd}$ & $11.333 \mathrm{a}$ & $6.333 \mathrm{a}$ \\
\hline Thailand & $11.220 \mathrm{abc}$ & $7.333 \mathrm{abcd}$ & $2.333 \mathrm{bc}$ \\
\hline IP-1M & 6.420 ef & $3.000 \mathrm{e}$ & $2.000 \mathrm{bc}$ \\
\hline IP-2P-3-4-1 & $9.370 \mathrm{~cd}$ & $8.667 \mathrm{abc}$ & $3.000 \mathrm{bc}$ \\
\hline Rataan & 7.998 & 6.438 & 2.635 \\
\hline
\end{tabular}

Keterangan : Angka-angka pada kolom yang sama dan diikuti huruf yang berbeda menunjukkan berbeda nyata berdasarkan uji DMRT pada taraf 5\%. Hasil transformasi akar $(x+0.5)$

Dompu, IP-2P-3-4-1, Bima M, Medan I-5-1, dan Banten I-3-1 mengalami panen puncak pada bulan kedua (Juni), dimana pada bulan ini kelimanya mampu memproduksi lebih dari 100 buah. Genotipe Bima F juga mengalami panen puncak pada bulan kedua, yaitu bulan Juli, dengan hasil 89 buah dan rata-rata buah per bulan 66 buah.

Bobot biji kering 16 genotipe jarak pagar berkisar 7.44 - 67.90 g tanaman-1 dengan bobot rata-

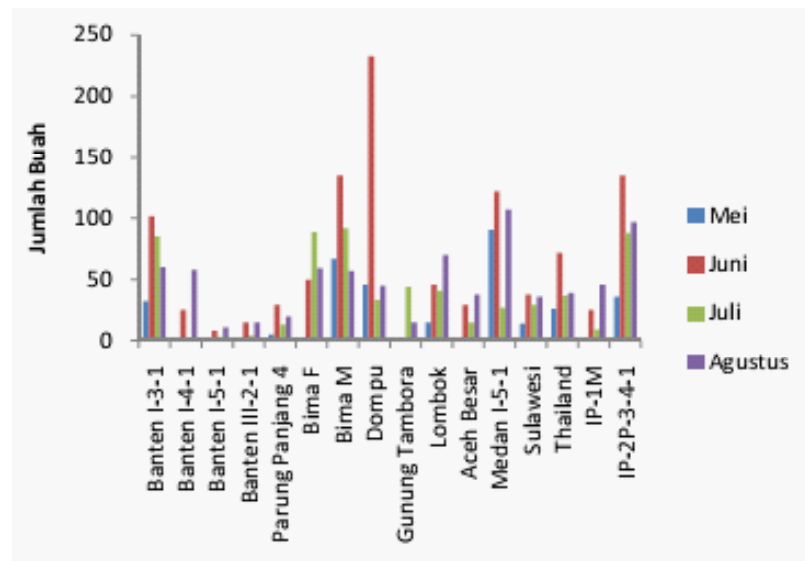

Gambar 2. Jumlah buah panen 16 genotipe jarak pagar selama empat bulan rata $36.81 \mathrm{~g}$ tanaman-1. Bobot biji kering tertinggi dimiliki oleh genotipe IP-2P-3-4-1, kemudian Medan I-5-1 dan Bima F, sedangkan bobot biji kering terendah terdapat pada genotipe Banten I-5- 1, kemudian Banten III-2-1. Hasilpenelitianmenunjukkan bahwa buahyang dihasilkan Medan I-5-1 lebih banyak dibandingkan dengan IP-2P-3-4-1, tetapi bobot biji kering IP-2P-34-1 lebih tinggi dibandingkan Medan I-5-1 (Tabel 7). Hasil ini menunjukkan bahwa genotipe IP-2P-3-4-1 menghasilkan biji yang lebih banyak dibandingkan Medan I-5-1, meskipun begitu perbedaannya tidak nyata dimana selisih bobot biji kering keduanya adalah $2.61 \mathrm{~g}$. Perbedaan yang nyata terjadi antara IP-2P-3-4-1 dengan Dompu, dimana jumlah buah yang dihasilkan kedua genotipe ini tidak berbeda nyata, tetapi bobot biji kering yang dihasilkan IP2P-3-4-1 nyata lebih tinggi dibandingkan Dompu dengan selisih $10.80 \mathrm{~g}$. Genotipe dengan penampilan terbaik berdasarkan peubah jumlah buah per malai, jumlah buah per tanaman, jumlah buah per bulan, dan bobot biji kering adalah IP-2P-3-4-1, Medan I-51, dan Dompu. Sementara itu genotipe dengan yang memiliki nilai terendah berdasarkan peubah- peubah tersebut adalah Banten I-5-1 dan Banten III-2-1. 
Tabel 7. Jumlah buah per malai, jumlah buah per tanaman, dan bobot biji per tanaman 16 genotipe jarak pagar di tanah masam

\begin{tabular}{|c|c|c|c|c|c|}
\hline \multirow{2}{*}{$\begin{array}{l}\text { Genotipe } \\
\text { Ban I-3-1 }\end{array}$} & $\begin{array}{c}\text { Jumlah Buah } \\
\text { Malai-1 } \\
\end{array}$ & \multicolumn{2}{|c|}{$\begin{array}{c}\text { Bobot } \\
\text { Buah Tan-1 }\end{array}$} & \multicolumn{2}{|c|}{$\begin{array}{c}\text { Bobot BK } \\
(\mathrm{g})\end{array}$} \\
\hline & $7.483 \mathrm{ab}$ & 31 & $a b$ & 43.49 & abcd \\
\hline Ban I-4-1 & $4.557 \mathrm{~cd}$ & 14 & bcde & 20.30 & bcdef \\
\hline Ban I-5-1 & $3.667 \mathrm{~cd}$ & 5.333 & $\mathrm{e}$ & 7.44 & $f$ \\
\hline Ban III-2-1 & $2.835 \mathrm{~d}$ & 6.5 & $\mathrm{e}$ & 10.27 & ef \\
\hline Parung P4 & $6.097 \mathrm{bc}$ & 22.333 & abcd & 35.25 & abcde \\
\hline Bima F & $6.23 \mathrm{bc}$ & 26 & abcd & 34.78 & abcdef \\
\hline Bima M & $9.037 \mathrm{a}$ & 38.667 & $\mathrm{a}$ & 57.10 & $\mathrm{a}$ \\
\hline Dompu & $10.113 \mathrm{a}$ & 39.667 & $\mathrm{a}$ & 53.23 & $a b$ \\
\hline G.Tambora & $3.860 \mathrm{~cd}$ & 12 & cde & 15.31 & def \\
\hline Lombok & $5.203 \mathrm{bcd}$ & 21.667 & abcd & 36.09 & abcde \\
\hline Aceh Besar & $2.953 \mathrm{~d}$ & 10 & de & 18.12 & cdef \\
\hline MedanI-5-1 & $7.817 \mathrm{ab}$ & 43 & $\mathrm{a}$ & 65.29 & $\mathrm{a}$ \\
\hline Sulawesi & $7.557 \mathrm{ab}$ & 35.333 & $\mathrm{a}$ & 57.27 & $a b$ \\
\hline Thailand & $7.647 \mathrm{ab}$ & 29 & $a b c$ & 50.47 & $a b c$ \\
\hline IP-1M & $5.143 \mathrm{bcd}$ & 10.333 & cde & 16.59 & cdef \\
\hline IP-2P-3-4-1 & $7.813 \mathrm{ab}$ & 39.333 & $\mathrm{a}$ & 67.90 & $\mathrm{a}$ \\
\hline Rataan & 6.126 & 24.01 & & 36.806 & \\
\hline
\end{tabular}

Keterangan : Angka-angka pada kolom yang sama dan diikuti huruf yang berbeda menunjukkan berbeda nyata berdasarkan uji DMRT pada taraf $5 \%$. Hasil transformasi akar $(x+0.5)$

Tabel 8. Seleksi 16 genotipe jarak pagar berdasarkan delapan peubah terpilih

\begin{tabular}{lccccccccc}
\hline Genotipe & $\sum$ Daun & $\sum \mathrm{CP}$ & $\sum \mathrm{CPr}$ & $\sum \mathrm{MT}$ & $\sum \mathrm{BBM}$ & $\sum \mathrm{BM}$ & $\sum \mathrm{BT}$ & $\mathrm{BBK}(\mathrm{g})$ & $\mathrm{KT}$ \\
\hline BanI-3-1 & & & & $\sqrt{ }$ & $\sqrt{ }$ & & & & 2 \\
BanI-4-1 & $\sqrt{ }$ & $\sqrt{ }$ & & & & & & & 2 \\
BanI-5-1 & $\sqrt{ }$ & & & & & & & & 1 \\
BanIII-2-1 & $\sqrt{ }$ & & & & & & & & 1 \\
Parung P4 & & & & $\sqrt{ }$ & & & & & 1 \\
Bima F & $\sqrt{ }$ & $\sqrt{ }$ & $\sqrt{ }$ & & & & & & 3 \\
Bima M & & & & & $\sqrt{ }$ & $\sqrt{ }$ & $\sqrt{ }$ & $\sqrt{ }$ & 4 \\
Dompu & & & $\sqrt{ }$ & & $\sqrt{ }$ & $\sqrt{ }$ & $\sqrt{ }$ & $\sqrt{ }$ & 5 \\
G.Tambora & $\sqrt{ }$ & $\sqrt{ }$ & & & & & & & 2 \\
Lombok & $\sqrt{ }$ & $\sqrt{ }$ & & & & & & & 2 \\
Aceh Besar & & & & & & & & & 0 \\
MedI-5-1 & & $\sqrt{ }$ & $\sqrt{ }$ & $\sqrt{ }$ & $\sqrt{ }$ & $\sqrt{ }$ & $\sqrt{ }$ & & 6 \\
Sulawesi & & & $\sqrt{ }$ & $\sqrt{ }$ & & & $\sqrt{ }$ & $\sqrt{ }$ & 4 \\
Thailand & & & & & $\sqrt{ }$ & $\sqrt{ }$ & & & 2 \\
IP-1M & & & & & & & & & 0 \\
IP-2P-341 & & & $\sqrt{ }$ & $\sqrt{ }$ & & $\sqrt{ }$ & $\sqrt{ }$ & $\sqrt{ }$ \\
\hline
\end{tabular}

Keterangan : $\sqrt{ }=$ menunjukkan nilai tertinggi yang dimiliki oleh masing- masing genotipe pada setiap peubah penyeleksi, $\mathrm{CP}=$ cabang primer, $\mathrm{CPr}=$ cabang produktif, $\mathrm{MT}=$ malai $\tan ^{-1}, \mathrm{BBM}=$ bunga betina malai ${ }^{-1}, \mathrm{BM}=$ buah malai ${ }^{-1}, \mathrm{BT}=$ buah $\tan ^{-1}, \mathrm{BBK}=$ bobot biji kering, $\mathrm{KT}=$ karakter Tertinggi 
Tabel 9. Pengaruh lima genotipe jarak pagar terseleksi terhadap tujuh peubah terpilih yang ditanam pada dua $\mathrm{pH}$ tanah berbeda

\begin{tabular}{|c|c|c|c|c|c|c|c|}
\hline Genotipe & $\sum \mathrm{CP}$ & $\sum \mathrm{CPr}$ & $\sum \mathrm{MT}$ & $\sum \mathrm{BBM}$ & $\sum \mathrm{BT}$ & $\sum \mathrm{BM}$ & $\mathrm{BBK}(\mathrm{g})$ \\
\hline \multicolumn{8}{|c|}{------------------------- pH 7.8 ------------------------------ } \\
\hline Medan & 3.8 & 3.3 & - & - & 35 & 8.3 & 41.96 \\
\hline Dompu & 7 & 2 & 2.2 & 4.8 & - & - & - \\
\hline IP-2P & 8 & 2 & 2.8 & 6.3 & - & - & - \\
\hline Bima M & 7 & 1 & 1.7 & 4.3 & - & - & - \\
\hline Sulawesi & 2 & - & 9.8 & 4.8 & 14.5 & 5.2 & 24.6 \\
\hline \multicolumn{8}{|c|}{-------------------- pH Asam (5.0) --------------------- } \\
\hline Med I-5-1 & 2 & 3.7 & 10.3 & 9.9 & 43 & 7.8 & 65.29 \\
\hline Dompu & 2 & 3.3 & 8 & 13.2 & 39.7 & 10.1 & 53.23 \\
\hline IP-2P-3-4-1 & 1.3 & 3 & 8.7 & 9.4 & 39.3 & 7.8 & 67.9 \\
\hline Bima M & 1 & 2.3 & 7.7 & 11.8 & 38.7 & 9 & 57.1 \\
\hline Sulawesi & 3.3 & 6.3 & 11.3 & 9.5 & 35.3 & 7.6 & 57.27 \\
\hline
\end{tabular}

Keterangan : $\quad \mathrm{BBM}=$ bunga betina malai ${ }^{-1}, \mathrm{BM}=$ buah malai $^{-1}, \mathrm{BT}=$ buah $\tan ^{-1}, \mathrm{BBK}=$ bobot biji kering.

Hasil seleksi dari 16 genotipe jarak pagar menunjukkan bahwa masing-masing genotipe jarak pagar memiliki keunggulan yang berbeda untuk setiap peubah terpilih. Berdasarkan seleksi pada delapan peubah terpilih terdapat lima genotipe jarak pagar yang potensial untuk dikembangkan di tanah masam, yaitu genotipe Medan I-5-1, Dompu, IP-2P-3-4-1, Sulawesi, dan Bima M. Hasil seleksi menunjukkan bahwa genotipe Medan I-5-1 memiliki karakter tertinggi untuk 6 peubah pengamatan, kemudian Dompu dan IP-2P-3-4-1 menunjukkan karakter tertinggi untuk 5 peubah, sedangkan Sulawesi dan Bima M memiliki karakter tertinggi untuk 4 peubah terpilih (Tabel 8).

Jarak pagar tergolong toleran terhadap tanah masam jika pertumbuhan dan produksi tanaman di lahan masam tidak berbeda nyata dengan jarak pagar yang ditanam di lahan dengan $\mathrm{pH}$ normal (6.0 - 7.5). Data pada Tabel 9 menunjukkan bahwa jarak pagar genotipe Medan I-5-1, Dompu, IP-2P3-4-1, Sulawesi, dan Bima $\mathrm{M}$ tergolong toleran tanah masam karena pada pH 5.0 memiliki hasil yang lebih baik dibandingkan dengan genotipe yang sama saat ditanam pada lahan dengan $\mathrm{pH} 7.8$ berdasarkan peubah jumlah cabang produktif, jumlah malai per tanaman, jumlah bunga betina per malai, jumlah buah per tanaman, jumlah buah per malai, dan bobot biji kering per tanaman. Sebaliknya, perbedaan sangat nyata terjadi pada genotipe IP-2P, Dompu, dan Bima $\mathrm{M}$ yang menghasilkan $1-2$ cabang primer pada $\mathrm{pH}$ 5.0 , sementara saat ditanam pada lahan dengan $\mathrm{pH}$ 7.81 menghasilkan $7-8$ cabang primer. Jadi jarak pagar genotipe IP-2P, Dompu, dan Bima M tergolong kurang toleran tanah masam berdasarkan peubah jumlah cabang primer.

\section{KESIMPULAN}

Genotipe-genotipe jarak pagar yang ditanam di lahan dengan $\mathrm{pH} 5.0$ menunjukkan keragaman pertumbuhan, baik pada fase vegetatif maupun fase generatif. Sebagian keragaman disebabkan potensi genetik dari setiap genotipe jarak pagar, namun sebagian lagi menunjukkan keragaman pertumbuhan karena faktor lingkungan, seperti kondisi tanah masam, cuaca, gangguan hama dan penyakit.

Terdapat lima genotipe jarak pagar yang menunjukkan pertumbuhan terbaik di tanah masam, yaitu Medan I5-1, Dompu, IP-2P-3-4-1, Sulawesi, dan Bima M.

\section{UCAPAN TERIMA KASIH}

Penulis menyampaikan terima kasih kepada Dinas Pertanian Kabupaten Bogor yang telah memberi izin menggunakan lahan untuk penelitian. Ungkapan terima kasih juga kami sampaikan kepada SBRC (Surfactant and Bioenergy Research Centre) IPB yang telah mendanai penelitian.

\section{DAFTAR PUSTAKA}

Giwangkara, E.G. 2006. Jarak Pagar Lebih Fleksibel dari Kelapa Sawit. http://persembahanku. 
wordpress.com. [14 Februari 2011].

Hartati, R.R. S, A. Setiawan, B. Heliyanto, D. Pranowo, Sudarsono. 2009. Keragaan morfologi dan hasil 60 individu jarak pagar (Jatropha curcas 1.) terpilih di kebun percobaan Pakuwon Sukabumi. Jurnal Littri 15(4):152-161.

Mahmud, Z. 2006. Budidaya jarak pagar untuk sumber energi masa depan. Buletin Warta Pengembangan dan Penelitian Pertanian 28(4):2.

Melisa. 2011. Karakterisasi Morfologi dan Agonomi 13 Aksesi Jarak Pagar (Jatropha curcas L.). Skripsi. Departemen Agonomi dan Hortikultura, Institut Pertanian Bogor. Bogor. 78 hal.

Misnen. 2010. Penapisan genotipe jarak pagar (Jatropha curcas 1.) untuk toleransi terhadap kekeringan. Tesis. Sekolah Pascasarjana, Institut Pertanian Bogor. Bogor.

Nisya, F.N. 2010. Analisis keragaman genetik jarak pagar (Jatropha curcas L.) berdasarkan karakter morfologi, agonomi, dan marka RAPD. Tesis. Sekolah Pascasarjana, Institut Pertanian Bogor. Bogor. 86 hal.

Nursanti, I., A.M. Rohim. 2009. Pengelolaan
Kesuburan Tanah pada Lahan Kering (Bagian 2). http://dasar2ilmutanah.blogspot. com. [21 Maret 2010].

Pambudi, N.A. 2008. Potensi Jarak Pagar Sebagai Tanaman Energi di Indonesia. http://www. chemistry.org/. [21 Mar 2010].

Prasetyo, E.I. Sukardjo, H. Pujiwati. 2007. Pertumbuhan dan hasil jarak pagar pada berbagai pola tanam di lahan marjinal. Jurnal Ilmu-Ilmu Pertanian Indonesia, Edisi Khusus (3):409-417.

Raden, I., B.S. Purwoko, Hariyadi, M. Ghulamahdi, E. Santosa. 2009. Pengaruh tinggi pangkasan batang utama dan jumlah cabang primer yang dipelihara terhadap produksi minyak jarak pagar (Jatropha curcas L.). Jurnal Agron. 37(2):159-166.

Santoso, B.B., Hariyadi, B.S. Purwoko. 2009. Pertumbuhan bibit jarak pagar asal biji dan stek pada berbagai macam media pembibitan. Crop Agro. 2(2):88-98.

Sumpena 2007. Pengembangan Tanaman Jarak Pagar (Jatropha curcas L.) http://sumpena. wordpress.com. [14 Februari 2011]. 